\title{
Mujeres migrantes en la ciudad global: ¿nuevas identidades?
}

\author{
Laura Echavarría Canto
}

\section{I}

\section{ntroducción}

El presente trabajo presenta un análisis del papel laboral y de las configuraciones subjetivas de los migrantes mexicanos en el espacio de la ciudad global, en particular la ciudad de Nueva York, y en las reconfiguraciones subjetivas de las mujeres en estos nuevos espacios de la globalización en su vínculo con la posibilidad de prácticas democráticas emergentes que posibiliten nuevos marcos de participación y empoderamiento del género femenino.

\section{Ciudades globales: espacios de la trasnacionalización laboral}

Como se sabe, la operación de la economía global requiere constituir espacios abocados al control de las principales actividades económicas para la ejecución de la red económica mundial, es decir, de estructuras centralizadas para participar en la economía globalizada, las llamadas ciudades informacionales, ciudades poscoloniales o ciudades globales. ${ }^{1}$ Castells plantea:

La economía informacional/global se organiza en torno a centros de mando y control, capaces de coordinar, innovar y gestionar las actividades entrecruzadas de los centros empresariales [...] Así pues, el fenómeno de la ciudad global no puede reducirse a unos cuantos núcleos urbanos del nivel superior de la jerarquía. Es un proceso que implica a

${ }^{1}$ Manuel Castells, La era de la información. Economía, sociedady cultura. México, Siglo XXI, 1999 y Saskia Sassen, "La economía informal en la ciudad de Nueva York", en Florencia Peña, ed., Estrategias femeninas ante la pobreza. El trabajo domiciliario en la elaboración de prendas de vestir. México, INAH, 1998. 
los servicios avanzados, los centros de producción y los mercados de una red global, con diferente intensidad y a una escala distinta según la importancia relativa de las actividades ubicadas en cada zona frente a la red global. ${ }^{2}$

Estas ciudades globales, en tanto estructura de participación en la economía globalizada, tienen diferentes funciones: espacios de coordinación del capital trasnacional; lugar de conexión entre la zona industrial y la zona de servicios; sitios de conexión entre las élites mundiales; fronteras donde se constituyen relaciones sociales fuertemente marcadas por género, etnia y clase; medios de reconstitución simbólica, y como locus de formación de imaginarios. Asimismo, estas ciudades resultan lugares esenciales no sólo para la organización del capital global, sino también para la trasnacionalización de la mano de obra, pilar fundamental de la fábrica global. ${ }^{3}$

Valenzuela considera que existen cinco puntos de acuerdo desde los que nos es posible estudiar a dichas ciudades, éstos son:

a) Las ciudades globales son nodos que articulan las economías locales, nacionales e internacionales a una economía global.

b) Se reconoce una coexistencia de espacios de acumulación global con espacios de economía de subsistencia, que son la mayoría.

c) Las ciudades globales son grandes espacios urbanizados con una intensa interacción social y económica.

d) Las ciudades globales pueden ordenarse de manera jerárquica de acuerdo con su poder económico, sus articulaciones, desde el orden nacional hacia el global, su capacidad de atracción de inversión, de respuesta a cambios externos en la tecnología y el cambio político.

${ }^{2}$ M. Castells, op. cit., p. 411.

${ }^{3}$ De acuerdo con diversos teóricos (Octavio Ianni, Teorías de la globalización. México, Siglo XXI, 1996; Leonel Corona, "Revolución científico-técnica", en La educación superior ante los desafíos de la sustentabilidad. México, ANUIEs, 1999, vol. I, pp. 42-56, y James Petras, "El imperio y los trabajadores: Estados Unidos y América Latina", en Eseconomía, núm. 3. México, Instituto Politécnico Nacional, 2003, pp. 5-17), una de las principales consecuencias de la globalización sobre el mundo del trabajo es lo que se conoce como la nueva división internacional del trabajo, producto de la intensa y generalizada internacionalización del proceso productivo, en donde se reproduce una organización del proceso de trabajo y producción caracterizada por la subcontratación, la precarización y la flexibilización de las condiciones laborales. Este proceso, también conocido como la "fábrica global", conlleva un giro radical del capitalismo, el cual desborda las fronteras nacionales y subsume a otras formas de organización social y técnica del trabajo, de la producción y de la acumulación de capital. 
e) Puede haber una clase social denominada "clase capitalista trasnacional" con intereses definidos alrededor del sistema global de acumulación; una cultura cosmopolita y una ideología consumista que coexiste con las demandas y el conflicto de las clases subalternas, estos últimos con intereses más locales y territoriales. ${ }^{4}$

En este sentido, estas ciudades globales actúan como centros de operación de las actividades económicas que acompañan a la globalización, es decir, de aquellas dedicadas a la imbricación entre sociedad del conocimiento y desarrollo tecnológico de punta o a aquellas que se ubican en la operación de la red financiera mundial o en los flujos de comunicación y transporte internacional, y en este aspecto concentran a empleados altamente calificados, aunque no por ello dejan de ser construidas y sostenidas por el trabajo no calificado, que mantiene a sectores estratégicos (servicios, construcción) y es lugar de incorporación de inmigrantes. Pero es un modo de incorporación que vuelve a estos migrantes trabajadores invisibles, en este aspecto, los inmigrantes irrumpen de manera semejante al proletariado subcontratado de los países periféricos, pero en una modalidad que oculta su trabajo en la producción material de la ciudad al lado de una exclusión que se legitima en función de ser considerados trabajadores innecesarios o desechables.

Para la ciudad global de Nueva York, Sassen señala:

En el trabajo diario del conjunto de servicios principales dominados por las finanzas, una gran parte de los empleos involucrados son de bajo salario y manuales, muchos llevados a cabo por mujeres e inmigrantes. Si bien estos tipos de trabajadores y empleos nunca son representados como parte de la economía global, ellos son, de hecho, parte de la infraestructura de trabajos involucrados en el funcionamiento y la implementación del sistema económico global. ${ }^{5}$

En este sentido, son las actividades de estos trabajadores poco especializados o manuales las que se encuentran ligadas tanto a la construcción material de la ciudad global (12\% de los inmigrantes mexicanos laboran en la industria de la construcción), como a la operación cotidiana de dicha ciudad ( $21 \%$ de los inmigrantes mexicanos trabajan en servicios domésticos, otro $14 \%$ se

${ }^{4}$ María Basilia Valenzuela, "Las condiciones de llegada y asentamiento de nuevos migrantes en ciudades globales. El caso de los mexicanos en el Harlem hispano de Nueva York", en Papeles de Población, núm. 22. México, Universidad Autónoma del Estado de México, 1999, p. 74.

${ }^{5}$ S. Sassen, Los espectros de la globalización. México, FCE, 2003, p. 118. 
encuentra empleado en la preparación de alimentos y un 13\% se dedica a labores agrícolas $)^{6}$ y señalan una materialidad del trabajo que se invisibiliza.

De esta manera, los migrantes que en general realizan estos trabajos invisibles son los que construyen materialmente a la ciudad (industria de la construcción) y su operación cotidiana (sector servicios), generan nuevas economías del afecto $^{7}$ (el trabajo doméstico de cuidado de niños o ancianos, altamente demandado por las nuevas élites gerenciales), pero enraizados en entramados de poder y de clase donde son vistos como sujetos prescindibles. Esto genera, a nivel simbólico, un deterioro de la subjetividad, que conlleva una producción social de la diferencia al servicio del poder y de la acumulación de capital.

\section{La ciudad de Nueva York}

Durante el siglo XIX, Nueva York se convirtió en una de las principales ciudades receptoras de inmigración proveniente de todos los países del mundo a través de la puerta de Ellis Island (isla de las lágrimas), una pequeña isla ubicada al lado de la Estatua de la Libertad en la bahía de Nueva York, donde se calcula que de 1892 a 1954 entraron a Estados Unidos entre 12 y 16 millones de emigrantes.

Es llamada así porque a muchos inmigrantes no se les permitió la entrada al país a pesar de que los veían enfrente de la isla, de acuerdo con Perec, "El $2 \%$ de los emigrantes fue rechazado. Esto representa, aunque parezca poco, doscientos cincuenta mil personas. Tres mil de ellas se suicidaron en Ellis Island entre 1892 y 1924". 8 Asimismo y de acuerdo con este mismo autor: "Era la Golden Door, la puerta de oro. Era allí, muy cerca, casi al alcance de la mano, la América mil veces soñada, la tierra de la libertad donde todos los hombres eran iguales, el país donde todos tendrán finalmente su oportunidad, el mundo nuevo, el mundo libre donde una vida nueva iba a poder comenzar".

Si bien, Estados Unidos es una nación que se construyó a partir de la migración, ${ }^{10}$ la importancia de Ellis Island está fuera de duda, de hecho "se

${ }^{6}$ Datos tomados de Jorge Durand, "Crisis y deportación”, en La Jornada. México, 10 de mayo de 2009.

${ }^{7}$ Puede verse el interesante documental de "Maid in America" que presenta diversos testimonios de trabajadoras de los servicios y su papel en esta nueva red de relaciones familiares.

${ }^{8}$ George Perec, Ellis Island. Buenos Aires, Libros del Zorzal, 2004, p. 19.

${ }^{9}$ Ibid., p. 19.

${ }^{10}$ Se calcula que en el siglo XviII llegaron más de medio millón de esclavos africanos. En la década de 1840 a 1850 , llegaron alrededor de un millón y medio de inmigran- 
calcula que el $40 \%$ de los estadounidenses tiene su genealogía al menos en un antepasado que llegó al país a través de este puerto". ${ }^{11}$ Ya desde entonces, la migración era ordenada y disciplinada de acuerdo a sistemas de razón fundamentados en procesos de exclusión de acuerdo a la adscripción de clase y de status. De esta manera,

[...] los pasajeros que viajaban en primera y segunda al llegar a Nueva York no eran obligados a desembarcar para atravesar todo el proceso de inspección médica o legal de la isla. Ése no era el caso de los inmigrantes que llegaban en tercera clase. Después de unos viajes en condiciones sanitarias y de hacinamiento lamentables, a diferencia del resto de los pasajeros, los de tercera eran transportados a la isla para ser sometidos a los controles sanitarios y legales pertinentes. ${ }^{12}$

En este aspecto, podemos acordar con Todorov ${ }^{13}$ en cuanto a su planteamiento de que hay dos modos de relación que el colonizador establece hacia el colonizado, los cuales persisten hasta nuestros días. El colonizador puede vislumbrar al colonizado como análogo a él, proyectando sus propios valores, en una postura de asimilación, o bien, puede partir de la perspectiva de la diferencia, que se traduce en términos de superioridad para el colonizador y de inferioridad para el colonizado.

Lo anterior da cuenta de un sistema complejo de inclusión/exclusión como dispositivo que fundamenta a la construcción identitaria estadounidense, por un lado, establecen la diferencia, aquello a lo que se excluye como punto nodal de identificación: primero fueron los amerindios los colonizados; posteriormente los africanos, los esclavizados, actualmente, el racismo se centra en los latinos y los mexicanos; por otro lado, intervienen estrategias de inclusión como puede observarse en la política asimilacionista que operó en la integración de los inmigrantes de Ellis Island.

Estas políticas de integración tuvieron en su fundamento las necesidades del desarrollo del capitalismo y dieron origen a que Nueva York fuese en el pasado una fábrica de estadounidenses y que hoy sea una de las principales ciudades globales. En este sentido, Perec plantea:

tes, en una mezcla de europeos, chinos y latinoamericanos, estos dos últimos grupos arrastrados por la Fiebre de Oro de 1848, en California, además que con la firma del Tratado de Guadalupe Hidalgo el 2 de febrero de 1848, aproximadamente 100000 mexicanos se convirtieron en extranjeros en su propia tierra.

${ }^{11} C f$. http://genealogiablog.blogspot.com/2007/04/ellis-island.

${ }^{12}$ G. Perec, op. cit., p. 19.

${ }^{13}$ Tzvetan Todorov, La conquista de América. El problema del otro. México, Siglo XXI, 1997. 
Los inmigrantes que desembarcaron por primera vez en Battery Park no tardaron en percibir que lo que les habían contado sobre la maravillosa América no era del todo exacto: tal vez la tierra pertenecía a todos pero aquellos que habían llegado primero estaban ya servidos, y no podían evitar amontonarse de a diez en los tugurios sin ventanas de Lower East Side y trabajar quince horas al día. Los pavos no caían rostizados en los platos y las calles de Nueva York no estaban pavimentadas con oro. En realidad, la mayoría ni siquiera estaba pavimentada. Y comprendían entonces que se les había hecho venir para que ellos las pavimentaran. Y para cavar los túneles y los canales, construir las rutas, los puentes, las grandes represas, las vías del tren, limpiar los bosques, explotar las minas y las canteras, fabricar los automóviles y los cigarros, las carabinas y los trajes, los zapatos, las gomas de mascar, el corned-beef y los jabones, y construir rascacielos, aún más altos que aquellos que habían descubierto al llegar. ${ }^{14}$

Si bien, esta trasnacionalización de la fuerza de trabajo se explica por su papel en los procesos de acumulación y reproducción del capital no por ello deja de ser necesario problematizar elucidaciones monocausales de los desplazamientos y los itinerarios laborales de los migrantes cuyo impacto sobre los diversos lugares de llegada es, sin duda, diversificado y manifiesta diferentes lógicas de inserción internacional y regional.

Asimismo, es necesario tomar en cuenta que si los inmigrantes son admitidos porque sus intereses laborales coinciden con los requerimientos de la acumulación capitalista de la economía que los acoge; en el contexto de sus países de origen pueden estar migrando no sólo por razones económicas, sino también por persecuciones políticas o por guerras.

Por ello, es simbólico el poema de Emma Lazarus (1883) inscrito sobre la base de la Estatua de la Libertad, ${ }^{15}$ situada en la isla conjunta a Ellis Island y que plantea: "Déme el cansancio, la pobreza, de las masas agrupadas que anhelan respirar libre, la basura desgraciada de la orilla. Envíeme la tempestad de éstos, los sin hogar, a mí".

Actualmente, la ciudad de Nueva York es una de las principales ciudades globales, como quinta área metropolitana más grande del mundo, con 17 millones de habitantes, tiene una notoria influencia económica, un crecimiento

${ }^{14}$ G. Perec, op. cit., p. 61.

${ }^{15}$ La Estatua de la Libertad es un regalo del gobierno francés a Estados Unidos para conmemorar el 100 aniversario de la independencia americana y es una estatua de 151 pies de una mujer que sostiene un libro y una antorcha en alto: "la libertad iluminando al mundo". 
continuo y un importante rol económico y cultural. La ciudad produce mil millones de dólares al día y el 75\% del producto de la ciudad se genera en Manhattan, el PIB de Nueva York es mayor que los ingresos de 191 países (incluyendo países como Rusia, Bélgica, Holanda, Suiza y Suecia) y es un $20 \%$ superior al de 40 países africanos.

Como se señaló arriba, son los migrantes latinos, y particularmente los mexicanos, quienes realizan funciones en el ciclo de acumulación de capital, fuertemente acendradas por la globalización del neoliberalismo y, en este sentido, los migrantes forman parte de los procesos productivos capitalistas y auspician tanto la especulación de las remuneraciones de la fuerza de trabajo indocumentada como los ciclos de expulsión-inclusión del trabajo conforme al proceso de acumulación.

De acuerdo al informe Los neoyorquinos más nuevos, 2000: el Nueva York inmigrante del nuevo milenio, elaborado por el Departamento de Planeación del gobierno de esta ciudad,

[...] Un 43\% de la fuerza laboral de la ciudad está formado por migrantes que son mayoría en la industria manufacturera, en la construcción y en varios sectores de servicios. En relación con los migrantes mexicanos, éstos se concentran en Brooklyn y Queens, seguidos del Bronx y Manhattan y estaban entre los de ingresos medios bajos de Nueva York -21 284 dólares anuales los hombres y 16737 las mujeres. Sin embargo, sólo el 32\% de los hogares mexicanos estaban bajo el nivel de pobreza y los ingresos medios por hogar fueron de $85 \%$ del promedio total de la ciudad. Esto se explica en gran medida porque varios trabajadores viven en una sola casa. ${ }^{16}$

La ciudad de Nueva York es considerada la capital económica mundial y da cuenta de los procesos contradictorios que caracterizan a la ciudad global; por un lado, funge como nodo de la economía global y representa a una de las naciones más poderosas; en su espacio territorial agrupa funciones líderes de mando, producción y administración económica, es también un centro de poder político y control financiero y lugar de reunión de las élites profesionales; por el otro, es sitio de marcadas desigualdades sociales y recinto de recepción de numerosos migrantes que se insertan en actividades económicas caracterizadas por condiciones de trabajo sumamente precarias y por procesos de invisibilización laboral.

${ }^{16}$ David Brooks, "Migrantes extranjeros se apoderan de Nueva York", en La Jornada. México, 25 de enero de 2005. 
Lo anterior es claramente visible en la construcción material de la ciudad de Nueva York donde han sobresalido los llamados procesos de gentrificación que se refieren a la utilización del capital de espacios urbanos antaño correspondientes a las clases populares, sobre todo los que se ubican en el centro de la ciudad y que son reocupados como centros financieros o comerciales, al lado de un incremento significativo en la construcción de viviendas en los suburbios, esta industria de la construcción se caracteriza por ser intensiva en mano de obra. Sassen documenta:

La expansión de la fuerza de trabajo de alto ingreso, en conjunto con el surgimiento de nuevas formas culturales, ha llevado a un proceso de gentrificación o elevación social del área hacia una con grandes ingresos, que últimamente depende de la disponibilidad de una amplia oferta de trabajadores de bajo salario. La gentrificación es intensiva en mano de obra, mientras que la suburbanización hacia una clase media es intensiva en capital. ${ }^{17}$

En suma, Nueva York, como una de las principales ciudades globales funge como locus estratégico para la valorización y acumulación de capital y para la dirección y centralización de procesos económicos globales, es lugar clave para la concentración de recursos y poderes decisivos en la operación de la economía mundial y, a la vez, espacio de incorporación de inmigrantes en actividades que mantienen a sectores económicos estratégicos, pero cuyas labores suelen ser vistas como prescindibles e innecesarias.

\section{Nuevas identidades de las mujeres migrantes en la ciudad global}

En este contexto, en las ciudades globales destaca el hecho de que la trasnacionalización de la fuerza de trabajo que se inserta en trabajos precarios e invisibles se ha visto cada vez más conformada por mujeres, lo cual se explica por tres razones: la primera se refiere a que el incremento de la industria maquiladora en sus países de origen está generando un desarraigo a modos tradicionales de trabajo (sobre todo en la agricultura); la segunda alude a que dada la incorporación masiva de trabajadoras a la maquila se generan nuevos saberes laborales y procesos de occidentalización que colaboran con la propagación de vínculos económicos, culturales e ideológicos con los países

\footnotetext{
${ }^{17}$ S. Sassen, Los espectros de la globalización, p. 186.
} 
centrales; y, tercero, dado que estas trabajadoras maquiladoras han introyectado dispositivos de subordinación acordes a las condiciones de precarización laboral que se viven en la maquila, resultan idóneas para realizar empleos de bajos salarios en condiciones de flexibilización laboral que demandan los países centrales hacia los que migran.

Importantes investigaciones ${ }^{18}$ sobre la maquila muestran la vigencia del relato dominante sobre la idoneidad de la docilidad femenina para realizar, primero, el trabajo de la maquila y, segundo, para insertarse como trabajadoras migrantes en las ciudades globales. Sin embargo, desde el postestructuralismo feminista se ha cuestionado un uso generalizado de la docilidad de la mujer como criterio importante para su contratación en la industria maquiladora y proponiendo, de acuerdo con Salzinger, ${ }^{19}$ investigar los procesos mediante los cuales se establece el carácter generizado del poder laboral.

Asimismo, diversas investigaciones ${ }^{20}$ dan cuenta de la feminización de la fuerza de trabajo que está operando en mercados de trabajo segmentados donde coexisten, al lado de poderosas empresas trasnacionales, empresas nacionales debilitadas que se sustentan en la subcontratación y la flexibilización laboral, esta última en términos técnicos es conceptualizada por Hernández Laos y Aboites como:

[...] la capacidad de respuesta del sistema laboral de una empresa ante una reestructuración de sus acervos de capital y un cambio en las condiciones del mercado interno de trabajo. El punto central es la recomposición de la plantilla de trabajadores con base en las condiciones del mercado laboral y en la estrategia interna de cambio tecnológico y organizacional de las empresas. ${ }^{21}$

18 Norma Iglesias, La flor más bella de la maquiladora. México, SEP / Cultura, 1985 y Teresa Rendón, Trabajo de hombres y trabajo de mujeres. México, unam, CRIM, PUEG, 2003.

${ }^{19}$ Leslie Salzinger, "De los tacones altos a los cuerpos cubiertos: significados generizados en (la) producción de la industria maquiladora para la exportación de México", en Debate Feminista. México, núm. 18, 2007, pp. 3-30.

${ }^{20}$ María Fernández-Kelly y Anna García, "Trabajo y familia entre costureras hispanas de California y Florida"; María Mies, "Dinámica de la división sexual del trabajo y la acumulación de capital. Las trabajadoras del encaje de Narsapur, India", y S. Sassen, "La economía informal en la ciudad de Nueva York", en Florencia Peña, ed., Estrategias femeninas ante la pobreza. El trabajo domiciliario en la elaboración de prendas de vestir. México, INAH, 1998, pp. 79-100 y pp. 31-53.

${ }^{21}$ Enrique Hernández Laos y J. Aboites Aguilar, Hipótesis explicativas del comportamiento de la productividad industrial. México, UNAM, Facultad de Economía, 1994, pp. 85-99. 
Esta conceptualización deja de lado que la flexibilidad laboral involucra dispositivos disciplinarios que el trabajador introyecta como mecanismos de poder inherentes al cuerpo, como un proceso de subjetivación y subordinación que tiene implicaciones en la subjetividad del trabajador.

En las ciudades globales esta segmentación de las empresas se traduce en una duplicidad del mercado laboral, con un sector formal y otro informal, siendo características de este último, salarios bajos, falta de estructuras sindicales, contratación de trabajadores eventuales o de tiempo parcial (sobre todo de migrantes ilegales), creciente flexibilidad laboral y feminización del mercado laboral.

Esta situación puede observarse en la siguiente entrevista realizada a una trabajadora migrante clandestina en Nueva York:

Ea: ¿En la factoría como de cuánto es su salario?

Tm1:22 5.75 la hora.

Ea: ¿Cuántas horas trabaja?

Tm1: 40 horas a la semana.

Ea: ¿Tiene prestaciones?

Tm1: No, prestaciones no, lo único es que hay un autobús que viene por nosotras en la mañana o depende del turno que le toque y nos lleva a la factoría que está en el otro estado que es Nueva Jersey y después ellos nos regresan, o sea, no gasto en transporte.

Ea: ¿Le piden papeles para trabajar o puede trabajar sin papeles?, o sea, usted es ilegal.

Tm1: Puedo trabajar sin papeles.

Ea: ¿No tiene ni residencia ni ciudadanía?

Tm1: No.

Ea: ¿Es ilegal, completamente ilegal?

Tm1: Sí, totalmente.

Ea: ¿Tiene usted aguinaldo, seguro médico?

Tm1: No, nada, nada.

22 TM1: Obrera migrante ilegal. Entrevista realizada el 29 de marzo de 2007 en la ciudad de Nueva York, Estados Unidos. De aquí en adelante será referenciada como TM1. 


\section{Ea: ¿Nada más su salario?}

Tm1: Y vacaciones, una semana de vacaciones pagada al año.

En este contexto se observan dos tendencias aporéticas, por un lado, si bien la incorporación laboral de las mujeres migrantes a empleos precarios y de alta flexibilización laboral constituye un ámbito de subordinación a las necesidades de la globalización neoliberal, en tanto el sistema patriarcal opera también a través del sometimiento de las mujeres a la fábrica global y a las necesidades de la división internacional del trabajo, por el otro, al generar un salario, las mujeres se emancipan relativamente de su dependencia económica y esto les ha posibilitado el acceso tanto a la voz como a la decisión.

En el caso de la ciudad global de Nueva York, ya desde la primera gran migración europea de 1878, se pueden observar estas transformaciones en la subjetividad femenina. Un cartel de una migrante italiana expuesto en la isla de las Lágrimas plantea: "Vine a América, no a lavar ni a planchar, sino a ser una mujer independiente".

En este sentido, la incorporación de las mujeres a estructuras propias de esta ciudad global también representa un espacio de reconfiguración de su subjetividad porque el migrar no sólo implica un movimiento territorial, sino también moviliza y transfigura los marcos simbólicos e imaginarios y en esta medida reconfigura a la subjetividad.

En el caso de las mujeres migrantes, el género no sólo está marcado por la diferencia sexual sino que también involucra a la raza, a la sexualidad, a la historia, a la cultura, a la lengua y la posición social, entre otros parámetros identitarios, y si bien, el género, ${ }^{23}$ en tanto diferencia biológica que ha devenido desigualdad social y política, es similar a lo largo de las trayectorias de vida de las mujeres migrantes, en tanto adscripción biológica e identidad socialmente construida, la migración involucra para las mujeres nuevos marcos simbólicos e imaginarios.

Estos nuevos marcos no sólo tienen que ver con la emancipación económica sino también con que las distintas estructuras de las sociedades patriarcales son diversas en los diferentes países, por ejemplo, el marco legal de protección a los derechos de la mujer es mucho más efectivo y enérgico en Estados Unidos.

De esta manera, la identidad de estas mujeres migrantes muestra ciertas e incipientes transformaciones, en tanto que el grado de sujeción o el proceso de subordinación al hombre son socavados a partir no sólo de la independencia

${ }^{23}$ Entendiendo al género como construcción social que involucra la aceptación del orden simbólico asociado al sistema patriarcal hegemónico que involucra un proceso de diferenciación y subordinación de las mujeres al lado de la negación de los otros, principalmente de los gays y las lesbianas. 
económica de las mujeres sino también a partir de nuevos marcos legales. En una de las primeras entrevistas, uno de los testimonios relata: "Aquí las cosas no son como en México, aquí la ley te protege y obliga al padre a dar una pensión para los hijos, a pagar los gastos médicos, la escuela", ${ }^{24}$ así la identidad adquiere nuevos parámetros a partir de su articulación con otredades distintas.

Ahora bien, la reconfiguración de género de las mujeres migrantes alude no sólo a marcos históricos y legales distintos a los del país de origen sino también a dimensiones simbólicas e imaginarias nuevas, en uno de los relatos una mujer migrante narra: "Aquí no es como en México, una gringa puede tener su novio, pero los sábados sale con sus amigas y si le gusta alguien se va a la cama, sin problemas, su novio lo acepta. Te imaginas, en México, él sería un cornudo y a ti no te bajarían de ramera". ${ }^{25}$

En este sentido, los nuevos marcos simbólicos conllevan una transfiguración de la subjetividad de las mujeres, si bien no dejan de lado los dispositivos de heteronormatividad en tanto atribuciones desiguales asignadas a cada género que presenta complejos matices y complejidades, sí se observan mecanismos menos violentos a los que se ejercen en nuestro país para mantener la tradicional opresión de las mujeres, donde la sexualidad femenina ha sido continuamente reprimida y sujeta a la institucionalidad dominante: al servicio de la reproducción o de la prostitución, lo que les niega a las mujeres su emergencia como sujetos transgresores.

Sin embargo, estas nuevas posibilidades de transgresión sexual de los sistemas patriarcales por parte de las mujeres migrantes producen ámbitos de libertad y no por ello son en sí mismas prácticas de la libertad porque también instituyen representaciones asignadas por la cultura, la sociedad y el grupo social de pertenencia. ${ }^{26}$ En este sentido, Foucault plantea:

La liberación es en ocasiones la condición política o histórica para que puedan existir prácticas de libertad, [sin embargo] si consideramos por ejemplo, la sexualidad, es cierto que han sido necesarias una serie de liberaciones en relación con el poder del macho, que ha sido preciso liberarse de una moral opresiva que concierne tanto a la heterosexualidad

${ }^{24}$ Mujer migrante ilegal. Entrevista realizada el 29 de marzo de 2007, Nueva York, Estados Unidos.

${ }^{25}$ Mujer migrante ilegal. Entrevista realizada el 28 de marzo de 2007, Nueva York, Estados Unidos.

${ }^{26}$ Por ejemplo, la sociedad estadounidense ha asignado a la mujer afroamericana (en tanto, la Otra de la mujer blanca) una representación como sexualidad poderosa y excesiva, de tal suerte que la mujer afroamericana tendrá que subordinarse a esta representación, lo que deja de lado que la subjetividad femenina es también diferencia entre el papel que le asigna la sociedad y su propia subjetividad. 
como a la homosexualidad; pero esta liberación no permite que surja una sexualidad plena y feliz en la que el sujeto habría alcanzado al fin una relación completa y satisfactoria. La liberación abre un campo a nuevas relaciones de poder que hay que controlar mediante prácticas de libertad. ${ }^{27}$

En este aspecto, si la libertad sexual que priva en la sexualidad de las mujeres estadounidenses implica una liberación de patrones patriarcales de sumisión sexual e implica un ámbito de libertad, no necesariamente involucra una sexualidad plenamente realizada porque al dejarse de lado, aspectos tales como la amistad, el cuidado de sí que implica a su vez, el cuidado del otro, es decir, el saltar todas las prohibiciones, si bien es un ámbito de libertad, importante per se, en tanto en México, la prohibición de la sexualidad femenina es un fundamento del sistema patriarcal, no por ello deja de observarse y de acuerdo con Foucault que "...está totalmente ausente el problema ético de la práctica de la libertad: ¿cómo se puede practicar la libertad? En lo que se refiere a la sexualidad es evidente que es únicamente a partir de la liberación del propio deseo como uno sabrá conducirse éticamente en las relaciones de placer con los otros". 28

Por último, cabe señalar que los empoderamientos son fragmentados y sumamente precarios, no abarcan la totalidad de la vida de la mujer migrante porque ésta también está sometida (como se menciono anteriormente) a las necesidades de la fábrica global y a añejas subordinaciones de género, como podemos observar en el siguiente fragmento:

Ea: ¿En relación con México, cree usted que ha tenido posibilidades de desarrollo, ya sea escolar, o profesional o algún tipo de desarrollo?

Tm1: Sí hay oportunidades, más bien el que no me ha dejado es mi marido, no, pero si hay oportunidades de estudiar aquí, hay muchos programas en las escuelas para aprender el idioma, o para aprender alguna cosa con la que uno se pueda ganar la vida, que son clases de manicure o de cocina o de cosas así pero no, no he podido realmente aprovechar porque siempre ha sido un problema con mi esposo

Ea: No la deja.

Tm1: No.

${ }^{27}$ Michel Foucault, "La ética del cuidado de uno mismo como práctica de la libertad", en Hermenéutica del sujeto. Madrid, La Piqueta, 1994, p. 110.

${ }^{28}$ Ibid., p. 111. 
Ea: ¿Cuál es el motivo por lo que no la deja?

Tm1: Es muy celoso, muy celoso, sí.

Sin embargo, el acceso al mercado laboral, la independencia económica, la experiencia de migrar, los nuevos marcos simbólicos e imaginarios están posibilitando reconfiguraciones subjetivas, lo que está generando un nuevo estudio feminista sobre las mujeres migrantes que se concentra en cómo la migración internacional perturba los patrones de género y cómo la formación de hogares trasnacionales puede empoderar a las mujeres.

\section{A modo de cierre}

La ciudad global es un espacio donde predominan actividades financieras con un alto avance de nuevas telecomunicaciones y tecnologías de sistemas informáticos y con una creciente intensidad de servicios en la organización de la economía, lo anterior ha generado un importante incremento de profesionistas especializados con altos ingresos ligados a importantes áreas de la organización de la economía. Esta preeminencia del profesionalismo en la organización económica ha favorecido una valorización tanto económica como simbólica de los servicios especializados y de los trabajadores especializados, lo que ha generado una desvalorización tanto de actividades económicas como de trabajadores no especializados, los que se consideran innecesarios para una economía avanzada, aun cuando paradójicamente sean los trabajadores manuales los que participen en la construcción de esta ciudad global, lo anterior ha generado que el papel de los trabajadores migrantes y la feminización del mercado laboral en la construcción de la ciudad global se hayan visto invisibilizados.

La ciudad de Nueva York representa una de las principales ciudades globales, con una tradición histórica de migraciones diferenciadas, en la actualidad se caracteriza por ser polo de atracción para la migración ilegal que se inserta en trabajos pauperizados e inapreciados, incluso para sí mismos y en donde la fuerza de trabajo femenina es altamente requerida.

En este marco, las mujeres migrantes se encuentran en la ciudad global con referentes similares y distintos a los de su país de origen, éstos actúan sobre su identidad generando subjetividades aporéticas, en tanto, por un lado, reproducen patrones de vieja data, como la subordinación laboral en situaciones de precariedad, el sometimiento al sistema patriarcal, y aun cuando el acceso al salario podría ser pensado como factor de liberación, en tanto posibilita una relativa emancipación económica, dadas las condiciones de pauperización no es un elemento nuevo ni suficiente para pensarlo como elemento importante en la conformación de nuevas identidades. 
Por otro lado, los marcos legales de protección legal a los derechos de la mujer y los diferentes parámetros simbólicos, por ejemplo, respecto a la sexualidad, permiten vislumbrar que la subjetividad femenina puede adquirir nuevos parámetros a partir de su articulación con otredades distintas, ello no implica necesariamente que estos parámetros sean transgresores de la heteronormatividad ni que sean necesariamente emancipadores.

Por último, es necesario desarrollar investigaciones que nos permitan ubicar el impacto de esta relativa perturbación de los patrones de género que viven las mujeres migrantes en la ciudad global, bajo el intento de dar cuenta de la transformación de las subjetividades en los escenarios trasnacionales. 